\title{
RELAÇÕES ENTRE ELEMENTOS CLIMÁTICOS E GEOGRÁFICOS NAS OCORRÊNCIAS DE INCÊNDIO FLORESTAL NO PARQUE ESTADUAL DA PEDRA BRANCA-RJ
}

\author{
BRANDÃO, Cássia Barreto - cassiabbgeo@gmail.com \\ Prog Pós-graduação Geografia / UERJ - Univ. Estadual do Rio de Janeiro \\ MIRANDA, Ricardo Augusto Calheiros - rmirandauerj@gmail.com \\ Inst. Geografia / UFRJ - Univ. Federal do Rio de Janeiro
}

\begin{abstract}
RESUMO. Os incêndios florestais podem iniciar-se de forma espontânea ou ser consequência de ações e ou omissões humanas, mas mesmo nesse último caso, os fatores climatológicos e geográficos são decisivos para incrementá-los, facilitando sua propagação e dificultando seu controle. O presente estudo busca correlacionar os elementos climatológicos, geográficos e meteorológicos com a incidência de fogo em vegetação no Parque Estadual da Pedra Branca, localizado na região metropolitana no Rio de Janeiro. Durante a pesquisa foi possível estabelecer regiões mais susceptíveis a incêndios de acordo com o balanço hídrico climatológico, características geográficas e condições meteorológicas favoráveis. As vertentes situadas ao norte do maciço da Pedra Branca foram as que representaram elevadas incidências e maiores riscos futuros de ocorrências de incêndio, principalmente durante os meses de inverno devido à presença de deficiências hídricas e a condições de vegetação e topografia mais favoráveis ao incêndio. Nas demais regiões do parque o risco é menor, porém pode ser revertido à medida que o homem altera o material combustível florestal e as condições microclimáticas.
\end{abstract}

Palavras-chave: incêndio, vegetação, meteorologia, geografia.

RELATIONS BETWEEN CLIMATE AND SPATIAL ELEMENTS IN INSTANCES OF FOREST FIRE IN PARQUE ESTADUAL DA PEDRA BRANCA-RJ

ABSTRACT. Forest fires can start spontaneously or be the result of human actions and omissions, but even in the latter case, the geographical and climatological factors are decisive for the increment them, facilitating their spread and their control difficulting. The present study attempts to correlate the elements climatological, meteorological and geographical with the incidence of fire on vegetation at Parque Estadual da Pedra Branca, located in the metropolitan area in Rio de Janeiro. During the research it was possible to establish the regions most susceptible to fires according to the climatic water balance, geographical features and favorable weather conditions. the slopes of the massif located in the north of Pedra Branca were those that represented high incidences and risk future the occurrences of fire, especially during the winter months due to the presence of water deficiencies and conditions more favorable topography and vegetation. In other regions of the park the risk is less, but can be reversed measurement that the man changes the combustible forest material and the microclimate.

Keywords: fire, vegetation, weather, geography.

\section{INTRODUÇÃO}

Os incêndios florestais podem ocasionar prejuízos tanto humanos quanto ambientais, tendo também consequências econômicas como a destruição de habitat e custos no combate ao fogo. Os estudos sobre o impacto dos incêndios florestais em florestas tropicais tornam-se cada vez mais importantes à medida que os efeitos do fogo passam a ter repercussões negativas na natureza e a na sociedade.

O fogo é definido por uma reação química de oxidação com desprendimento de luz e calor (SOARES e BATISTA, 1985), sendo, portanto, a parte visível de uma combustão. A combustão é, portanto, uma reação química, logo, deve ter um mínimo de dois elementos que reajam entre si, bem como uma circunstância que permita dar partida a tal reação. Para que se inicie a combustão são indispensáveis três elementos básicos, a saber: o combustível, o comburente e uma fonte de calor. Na natureza o fogo se manifesta e se propaga diferentemente em função da composição química do material combustível disponível, pela exposição desse material ao calor e pelo teor de oxigenação e umidade contida no ar adjacente. Assim, a ocorrência de incêndios florestais, principalmente os de origem natural, é influenciada por fatores 
geográficos (tipo de vegetação, relevo e etc.) e por elementos do clima (temperatura, umidade do ar e vento).

O regime eólico predominante num local e/ou região pode afetar o comportamento do fogo auxiliando, por exemplo, na combustão do material pelo aumento e suprimento de oxigênio. 0 vento pode atuar como um elemento intensificador do fogo, carreando materiais acesos ou aquecidos para novos locais ou dirigindo as chamas para perto de outras áreas combustíveis (BROWN e DAVIS, 1973).

A umidade atmosférica é um dos elementos do clima mais importante na propagação de incêndios florestais. Dados sobre a ocorrência de incêndios florestais demonstram que, quando a umidade relativa do ar diminui ao nível de $30 \%$ ou menos o combate ao incêndio é dificultado. (GAYLOR, 1974; BATISTA, 1984).

A precipitação pluviométrica é fundamental, pois é a variável responsável pelo umedecimento do material combustível, dificultando o início e a propagação do fogo. Há uma grande correlação entre incêndios e os períodos de seca prolongados. A distribuição das chuvas é, portanto, fator fundamental na definição do início, término e duração das chamas (SOARES e BATISTA, 1985).

A temperatura do ar é um dos elementos meteorológicos que tem grande importância na origem dos incêndios, pois sua influência ocorre sobre a combustibilidade da mata, facilitando a evaporação e consequentemente diminuindo o grau de umidade da serrapilheira (MCIF, 2006).

A partir da análise climática do balanço hídrico é possível se determinar os períodos no ano em que se verificam maiores probabilidades de ocorrências de incêndios, facilitando assim, as medidas que requerem logística de combate e possibilitando a adoção de medidas de prevenção.

Assim sendo, em se tratando de ecossistemas naturais, a deflagração de um incêndio e a sua subsequente propagação se fazem em função de efeitos: topográficos, atmosféricos e bióticos.

$\mathrm{Na}$ região Sul e Sudeste do Brasil, os períodos compreendidos entre os meses de junho a outubro se caracterizam pela baixa umidade relativa do ar e pela escassez de chuvas, aumentando assim os riscos de incêndios florestais espontâneos (BATISTA, 2000). Se não bastasse o panorama climático desfavorável desse período do ano, associa-se também 0 hábito de moradores das áreas urbanas e rurais em utilizar o fogo como instrumento de eliminação de resíduos das mais diferentes naturezas, ocasionando incêndios descontrolados e de grandes proporções devido à conjuntura favorável.

Segundo informações divulgadas pelo Corpo de Bombeiros (CBMERJ, 2010), no caso específico da cidade do Rio de Janeiro, a expansão das favelas de maneira irregular, invadindo áreas de preservação, vêm contribuindo para o desequilíbrio ambiental, aumentando assim, o risco de incêndios florestais.

Segundo o Instituto Estadual do Ambiente (INEA), no período da chegada dos portugueses ao Brasil, estimava-se que $98 \%$ do território fluminense eram recobertos por Mata Atlântica e ecossistemas associados, como manguezais, restingas e campos de altitudes. Hoje, no entanto, calcula-se que menos de $17 \%$ da superfície do Estado do Rio de Janeiro estejam recobertos por Mata Atlântica. Antes da Mata Atlântica ser explorada intensivamente os incêndios florestais provavelmente ocorriam em uma frequência menor do que evidenciamos hoje. É por essa razão que o tema da preservação em remanescentes florestais, como o da Mata Atlântica, vítima de constantes incêndios naturais e criminosos vem sendo intensivamente investigado a partir da década passada (BATISTA, 1984; COSTA et al., 2003; GOLDAMMER, 1982 e MONTEZUMA e OLIVEIRA, 2010)

Os resultados a serem perseguidos por esse estudo se baseiam no fato de ser mais eficiente e vantajoso dedicar-se atenção à prevenção de incêndios do que à supressão propriamente dita. O conhecimento das características climatológicas regionais é essencial para diagnosticar áreas mais propícias a incêndios florestais, sendo o balanço hídrico climatológico o responsável por definir as áreas mais suscetíveis de acordo com a umidade do solo. Estudiosos como Coura et al. (2009) e Batista (2000) já consideram o balanço hídrico como peça chave no mapeamento de risco de incêndios. Estes autores, porém, também ressaltam a importância de informações relacionadas a características geográficas como: exposição do relevo a radiação solar e características vegetacionais.

Neste estudo procurou-se analisar as regiões mais propícias a incêndios no Parque Estadual da Pedra Branca de acordo com o balanço hídrico, séries históricas de temperatura e precipitação 
e características geográficas. O ano com maior número de registro de casos incêndio (2006) também foi trabalhado através de averiguações das condições do tempo em escala diária (relação do tempo X dia da ocorrência do incêndio).

\section{METODOLOGIA}

O Parque Estadual da Pedra Branca (PEPB) está localizado exatamente no centro geográfico do município do Rio de Janeiro, situado entre os paralelos $22^{\circ} 55^{\prime}$ e $23^{\circ} 05^{\prime}$ Sul e os meridianos $43^{\circ} 20^{\prime}$ e $43^{\circ} 40^{\prime}$ Oeste (FIGURA 1 ).

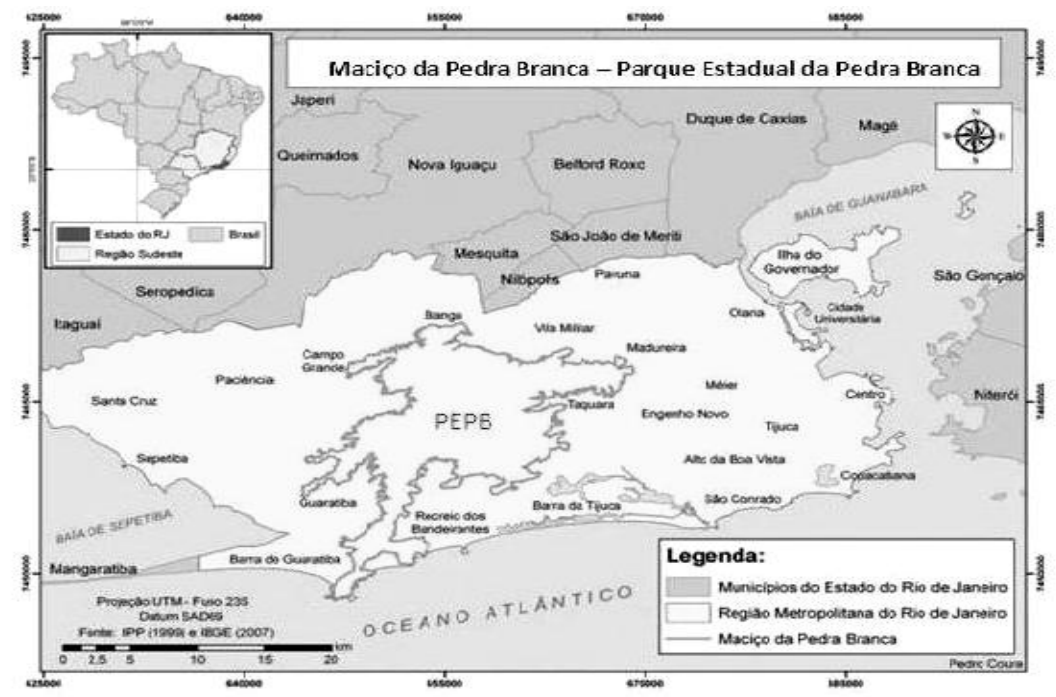

Figura 1 - Localização do Parque Estadual da Pedra Branca no Rio de Janeiro, Brasil. Fonte: Adaptado de COURA et al., (2009).

Em 1974, por meio da Lei Estadual $n^{\circ} 2.377$, o maciço da Pedra Branca a partir da cota de nível de 100 metros foi transformado em Parque Estadual. Em 1988, através de Lei Municipal de $n^{\circ} 1206$, as autoridades resolveram transformar as áreas acima da cota de $300 m$ em Área de Proteção Ambiental (APA) numa tentativa de combater a erosão e os efeitos causados pela ocupação desordenada das áreas de baixada circundante.

Nas porções Leste e Oeste do maciço da Pedra Branca, a barreira topográfica natural atua no deslocamento das massas de ar úmido em sua direção. Essas vertentes do maciço se destacam pela ocorrência de chuvas orográficas e por apresentarem áreas de maior adensamento florestal. Em contrapartida no seu lado oposto, a sotavento, a vegetação vai rareando devido à baixa umidade do ar, à escassez das chuvas orográficas e a maior exposição aos raios solares.

\section{Coleta e levantamento de dados. Ocorrências de incêndios}

dados das ocorrências de fogo em vegetação durante o período de 1999 a 2009 foram fornecidos pelo Centro de Operações do Corpo de Bombeiros, localizado no Quartel Central do Rio de Janeiro. Entre as informações cedidas e, posteriormente, catalogadas constam: data, mês, ano e o bairro de ocorrência do evento.

\section{Dados climatológicos}

Devido à variabilidade climática existente na cidade do Rio de Janeiro, tornou-se necessária a coleta de dados de estações representativas das vertentes Norte e Leste do Parque Estadual da Pedra Branca - PEPB.

Os dados pluviométricos foram coletados na GEO-RIO (Fundação Instituto de Geotécnica do Rio), através do site http://www2.rio.rj.gov.br/georio. Utilizou-se nesse estudo dados pluviométricos da estação de Jacarepaguá / Cidade de Deus e Bangu. Os dados de temperatura foram obtidos no Instituto Nacional de Meteorologia-INMET, utilizando-se dados 
da estação de Jacarepaguá, Bangu e Realengo como demonstra a tabela de localização dos postos de coleta de dados (TABELA 1).

Tabela 1

\section{Localização dos postos de coleta de dados climatológicos}

\begin{tabular}{|c|c|c|c|c|c|}
\hline \multicolumn{6}{|l|}{ Postos Pluviométricos-GEO-RIO } \\
\hline Bairros: & Long. (W) & Lat. (S) & UTM (E) & UTM (N) & Cota $(\mathrm{m})$ \\
\hline Bangu & $4327^{\prime} 55^{\prime \prime}$ & $22 \div 53^{\prime} 10^{\prime \prime}$ & 657,4 & 7468,22 & 15 \\
\hline Jacarepaguá-Cidade de Deus & $4321^{\prime} 44^{\prime \prime}$ & $22 \div 56^{\prime} 42^{\prime \prime}$ & 667,91 & 7461,59 & 15 \\
\hline \multicolumn{6}{|c|}{ Estação de monitoramento de Temperatura-INMET } \\
\hline \multicolumn{6}{|l|}{ Bairros: } \\
\hline Bangu & $4327^{\prime} 55^{\prime \prime}$ & $22 \circ 53^{\prime} 10^{\prime \prime}$ & $*$ & $*$ & $*$ \\
\hline Realengo & $22 \div 52^{\prime} 00^{\prime \prime}$ & $43 \div 25^{\prime} 00^{\prime \prime}$ & 662,4 & 7470,33 & 42 \\
\hline Jacarepaguá & $22 \circ 59 ' 16 "$ & $43 \div 22^{\prime} 13^{\prime \prime}$ & 667 & 7456,87 & 3 \\
\hline
\end{tabular}

Fonte: GEO-RIO; INMET (* não informado).

Para atender os objetivos desse estudo foram utilizados dados diários compensados da série histórica do Instituto Nacional de Meteorologia para a realização de estimativas das respectivas médias mensais de temperaturas em Bangu, pois esta possuía interrupções nas séries de dados. Para isso aplicou-se a metodologia proposta por Tronci et al., (1986), validada por Hubard (1999) pela qual um determinado elemento meteorológico pode, desde que apresente pequena dispersão em torno da sua média, ser estimado em função do inverso da distância entre a localidade desprovida de informações e a estação meteorológica de referência circunvizinha $\left(\mathrm{d}_{\mathrm{i}} ; \mathrm{km}\right)$, ou seja:

$$
V_{0}=\frac{\sum_{1}^{12} V_{i} / d_{i}}{\sum_{1}^{12} 1 / d_{i}} \quad \text { (Equação 1) }
$$

onde:

$\mathbf{V}_{\mathbf{0}}$ - elemento meteorológico a ser estimado;

$\mathbf{V}_{\mathbf{i}}$ - valor médio do elemento meteorológico correspondente ao mês na estação mais próxima;

Assim a estação utilizada para preencher as lacunas das respectivas médias mensais na estação climatológica de Bangu se refere à estação de Realengo, que se encontra a uma distância média de $3 \mathrm{~km}$ do bairro de referência.

Quanto à adoção da metodologia acima, Tronci et al. (1986) concluíram que, no caso de estimativas da temperatura e umidade relativa do ar em regiões de clima tropical, diferentemente, dos dados pluviométricos, a dispersão dos totais mensais e anuais em torno dos seus respectivos valores médios é em geral pequena $(\approx 5 \%)$. Permitindo que se verifique num raio de ação de até $100 \mathrm{~km}$ é muito pequena a variabilidade espaço temporal das temperaturas e da umidade (HUBARD, 1999).

Em uma análise pluviométrica de caráter temporal, Nieuwolt (1977) recomenda uma série mínima de 10 anos como referência de estabilidade. Assim sendo, considerando-se o compromisso entre a escolha de uma série histórica longa, aliada com a qualidade e disponibilidade de dados coletados em bairros circunvizinhos ao PEPB, escolheu-se o período de 1999 a 2009 para realização deste estudo.

Considerando-se que a região do Parque Estadual da Pedra Branca, devido a sua topografia, sofre maior irregularidade das chuvas por causa dos aspectos ligados à dinâmica atmosférica, que em última análise controla a sucessão dos tipos de tempo e clima, os estudos sobre a variabilidade deste fenômeno se tornam imprescindíveis (SANT' ANNA NETO, 1999).

Para se ter uma ideia mais aproximada das reais disponibilidades hídricas em qualquer região do planeta e em particular no maciço da Pedra Branca, onde o problema do déficit hídrico 
provoca grandes impactos sociais, não basta apenas que se conheça o regime pluviométrico, é necessária, também, a realização do balanço hídrico (PINTO et al., 2001)

O método de balanço hídrico de Thornthwaite \& Matter (1955) foi utilizado para realização dos cálculos. O nível de armazenamento de água no solo de $125 \mathrm{~mm}$ foi considerado como satisfatório de acordo com análises anteriores realizadas para cultura do café por Pinto (2001).

A classificação climática foi elaborada a partir do método proposto por Thornthwaite (1948), citado em Pereira et al., (2002). Utilizando os dados do balanço hídrico para cada período estudado determina-se o índice de aridez, que expressa deficiência hídrica em percentagem da evapotranspiração potencial, variando de 0 a 100 . Quando atinge o valo zero, significa que não existe déficit hídrico e quando alcança o valor 100, a deficiência é igual à evapotranspiração potencial. Este índice é calculado pela fórmula abaixo:

$$
I_{a}=\left[(D E F)_{\text {anual }} /(\text { ETP })_{\text {anual }}\right] \cdot 100 \text { (Equação 2) }
$$

Por fim, os dados foram reunidos em um esquema que representa as vulnerabilidades da vertente norte do maciço da Pedra Branca. Tal esquema foi baseado no uso e na cobertura do solo, no relevo, na meteorologia-climatologia e nos incêndios registrados entre 1999-2009. Tal esquema visa demonstrar quais áreas devem ser prioritárias na instalação de medidas mitigadoras de impactos gerados por incêndios florestais.

\section{RESULTADOS E DISCUSSÕES}

\section{Incêndios florestais no Parque Estadual da Pedra Branca}

Os gráficos apresentados nas (FIGURAS 2; 3) representam, respectivamente, o registro das ocorrências anual e mensal de incêndio florestais no Parque Estadual da Pedra Branca durante o período de 1999 a 2009. Foi registrado no Parque um total de (41) quarenta e uma ocorrências de incêndios florestais, sendo que, a maioria ocorreu na vertente norte do maciço circunvizinho aos bairros de Bangu e Realengo.

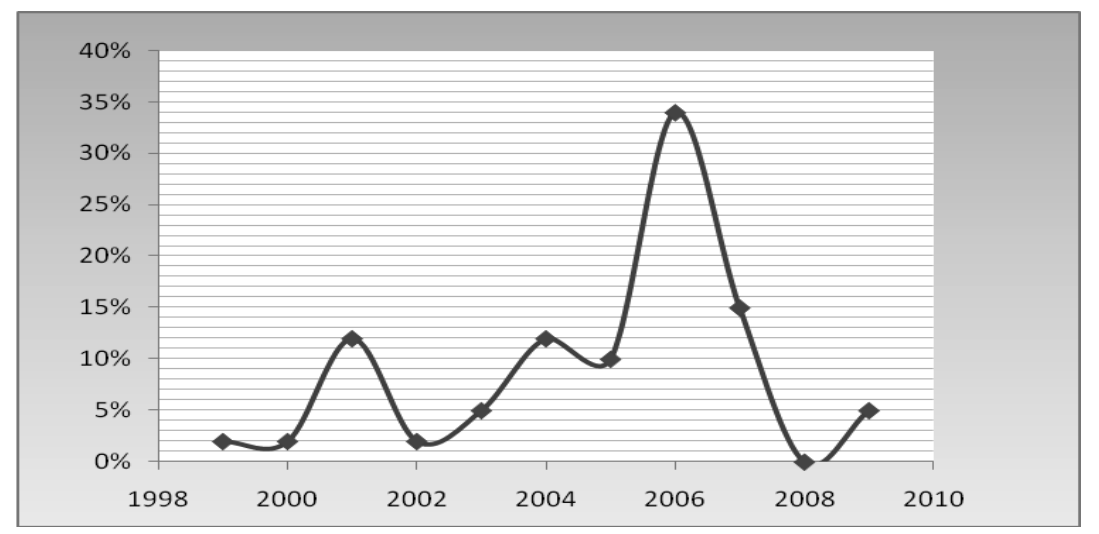

Figura 2 - Frequência anual de ocorrências de fogo em vegetação (1999-2009) Fonte: (BRANDÃO \& MIRANDA) 


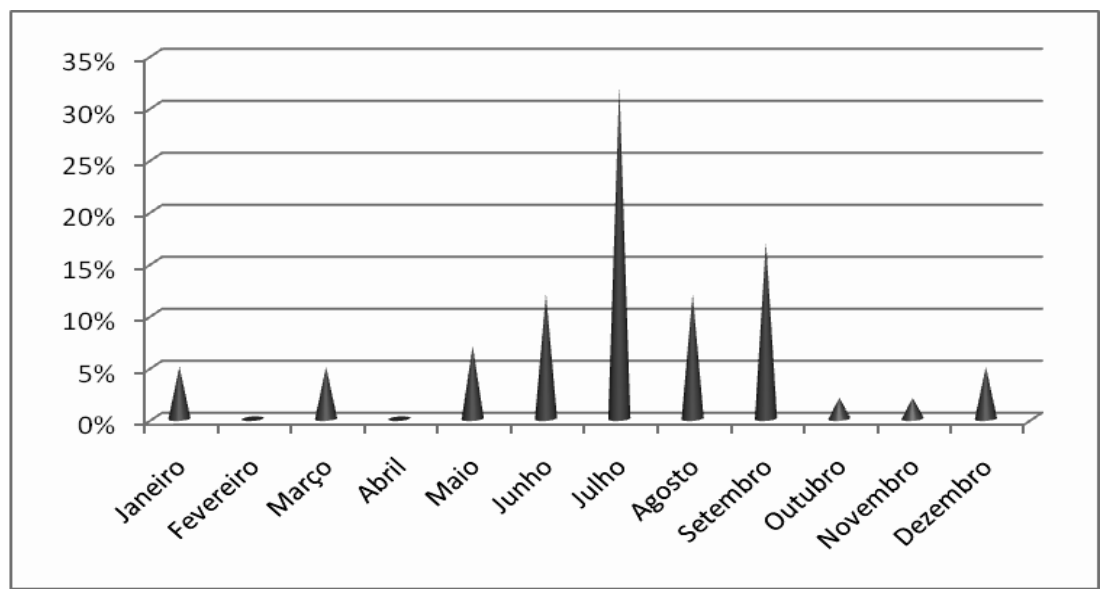

Figura 3 - Frequência mensal de ocorrências de fogo em vegetação (1999-2009) Fonte: (BRANDÃO \& MIRANDA)

De acordo com os dados apresentados na (FIGURA 2) observa-se que o ano de 2006 foi, na década, o ano que apresentou um maior percentual de ocorrências $(\approx 34 \%)$ de incêndios florestais no Parque Estadual da Pedra Branca. Em termos de variação mensal (FIGURA 3) do número de ocorrência de incêndios, observa-se que o período entre junho a setembro foi o que apresentou maior número de ocorrências, representando $65 \%$ das ocorrências dentre os registros anuais observados na (FIGURA 2).

De acordo com o CBMERJ (2010), no Rio de Janeiro, dentre as localidades circunvizinhas ao PEPB foi possível verificar que os bairros mais atingidos por incêndio na década estudada são: Realengo (61\%), seguido de Bangu (34\%), ambos localizados na vertente norte do maciço e Taquara (5\%) localizado na vertente leste. Baseado nesse fato é que se optou-se por analisar as séries históricas completas dos dados meteorológicos coletados em bairros localizados nos arredores da vertente norte (Bangu) e leste do maciço (Jacarepaguá) (FIGURA 4). Muito embora se tenha que enfatizar que a opção de utilizar dados coletados em Bangu e não em Realengo, onde o percentual de ocorrência de incêndios fora maior, foi devido à falta de séries de dados completos de chuva em Realengo.

Cabe destacar que a vertente oeste não apresentou nenhuma ocorrência de incêndio durante a série analisada, sendo, portanto, o estudo restrito as regiões onde houve alguma ocorrência de fogo em vegetação.

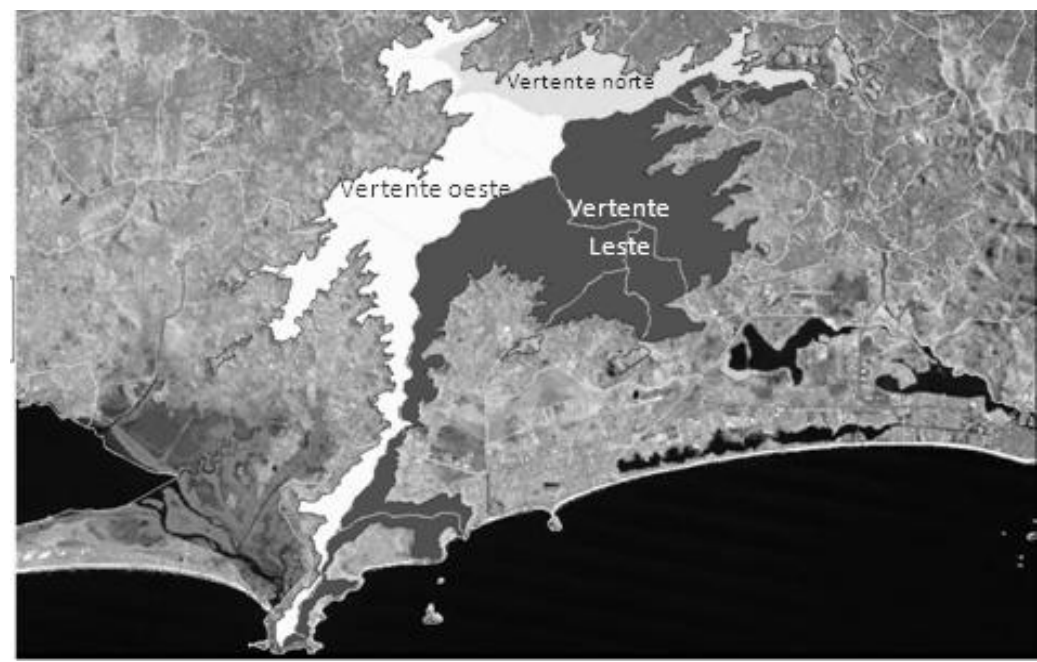

Figura 4 - Localização de vertentes do PEPB

Fonte: Base de dados disponível em: http://www.guiapepb.infotrilhas.com/pepb_1/pepb.html

Analisar a exposição do relevo aos raios solares é essencial para diagnosticar áreas mais propícias a incêndios florestais. No hemisfério Sul, por exemplo, os raios solares incidem mais diretamente sobre faces do relevo voltadas para o norte, transmitindo assim uma maior 
quantidade de calor para essa região do que para as faces voltadas para direção leste, oeste e sul. De acordo com Batista e Soares (2003), a face oeste é a segunda a receber maior quantidade de energia, seguida da face leste. A face sul é a que menos recebe radiação solar. Confirma-se então que a vertente norte do PEPB é a fração do maciço que mais recebe radiação solar, favorecendo a diminuição do teor de umidade do solo dessa e possibilitando a formação de condições mais propícias a incêndios.

As características vegetacionais também são essenciais para se avaliar a probabilidade de um incêndio. Na vertente norte do PEPB a vegetação é composta por campos e gramíneas, coincidindo com as áreas urbanizadas de Bangu e Realengo. Acredita-se que estas áreas se originaram de práticas do sistema de derrubada - pousio desenvolvidas no PEPB antes de sua criação (OLIVEIRA et al., 2009). Muitas destas áreas, por estarem localizadas predominantemente na vertente norte, onde há grande ocorrência de incêndios, e por não possuírem matrizes próximas, não são mais capazes de seguir o processo de sucessão ecológica natural e por essa razão permanecem como áreas inférteis e mais susceptíveis a incêndios. Daí a importância de se preservar as áreas de cotas de nível inferiores a 100m e que não estão inseridas na área de proteção do parque, pois as mudanças na vegetação das bordas do maciço podem favorecer a proliferação de vegetações de alto potencial de combustibilidade, como o capim-colonião, podendo contribuir para que um incêndio que comece fora da delimitação da área de proteção avance rapidamente para o interior da floresta, especialmente quando as condições de vento são favoráveis à propagação do fogo encosta acima.

$\mathrm{Na}$ vertente leste e oeste do maciço PEPB as atividades de derrubada-pousio foram praticamente abolidas após a sua criação, e com o tempo, a sucessão ecológica promoveu a cicatrização das clareiras (OLIVEIRA, 2005). Por conta disso, observa-se que grande parte das áreas de floresta se estende por toda fração oeste e leste do PEPB e pelo seu interior.

As vertentes voltadas para o leste e oeste usualmente recebem umidade proveniente das brisas marítimas e ao mesmo tempo em que recebem menor incidência de radiação solar. Desta forma, a recomposição da floresta nessa fração do maciço se dá em tempo relativamente curto e por isso se tornam menos suscetíveis a incêndios florestais do que as encostas voltadas para o norte (OLIVEIRA et al. 1995).

De acordo com os dados geográficos conclui-se que a vertente norte é mais favorável que a vertente leste e oeste em termos de incêndio florestal.

As análises das séries históricas de temperatura, precipitação e balanço hídrico em Bangu e Jacarepaguá possibilitaram nesse estudo demonstrar quais os locais e períodos em que há maior propensão a incêndios florestais. Mas deve-se salientar que há estudos dessa natureza que incorporaram análises de séries históricas de umidade relativa do ar e do regime eólico no local. Infelizmente, em se tratando do PEPB, essas informações foram abortadas, já que nesse local não se dispõe de registros completos destas variáveis nas estações utilizadas.

\section{Precipitação pluviométrica em Bangu e Jacarepaguá.}

Devido à sua localização e a complexidade climática provocada pela orografia da região estudada, a influência na circulação atmosférica sobre o local pode contribuir para a grande variabilidade espacial das chuvas precipitadas no local (DERECZYNSKI et al., 2009). Ou seja, em ambientes montanhosos é muito comum a ocorrência de chuvas do tipo orográfico, as quais se formam em decorrência do relevo acidentado, que obriga o ar a se elevar, perdendo temperatura e condensando o vapor de água, gerando a chuva. Assim sendo, considerou-se como representativas para análise dos dados pluviométricos as informações monitoradas em Bangu representando a vertente norte do maciço e as de Jacarepaguá representado a vertente leste do maciço do Parque Estadual da Pedra Branca - PEPB.

$\mathrm{Na}$ região do maciço da Pedra Branca, representada na (FIGURA 5), se observa que as principais características do regime pluviométrico local são a sua sazonalidade, identificada por um período mais seco (abril a setembro) e por um período chuvoso de outubro a março. Sendo que os meses de maio e setembro são, independentemente dos locais amostrados, considerados meses de transição de um regime para outro e, portanto, responsáveis por $13 \%$ do total médio anual registrando em Bangu $(1056 \mathrm{~mm})$ e Jacarepaguá (1108 mm), respectivamente. As maiores precipitações médias mensais ( $>100 \mathrm{~mm} / \mathrm{mês}$ ) concentram-se em Bangu nos meses de novembro a março. Em contrapartida, em Jacarepaguá nos meses de novembro, dezembro, janeiro e março são registrados médias mensais da precipitação 
pluviométrica nesse padrão. No trimestre mais seco (junho a agosto) se precipitam $9 \%$ (Bangu) e $14 \%$ (Jacarepaguá), respectivamente de um total anual entre 1056-1108 mm precipitado nas circunvizinhanças do Parque Estadual da Pedra Branca - PEPB.

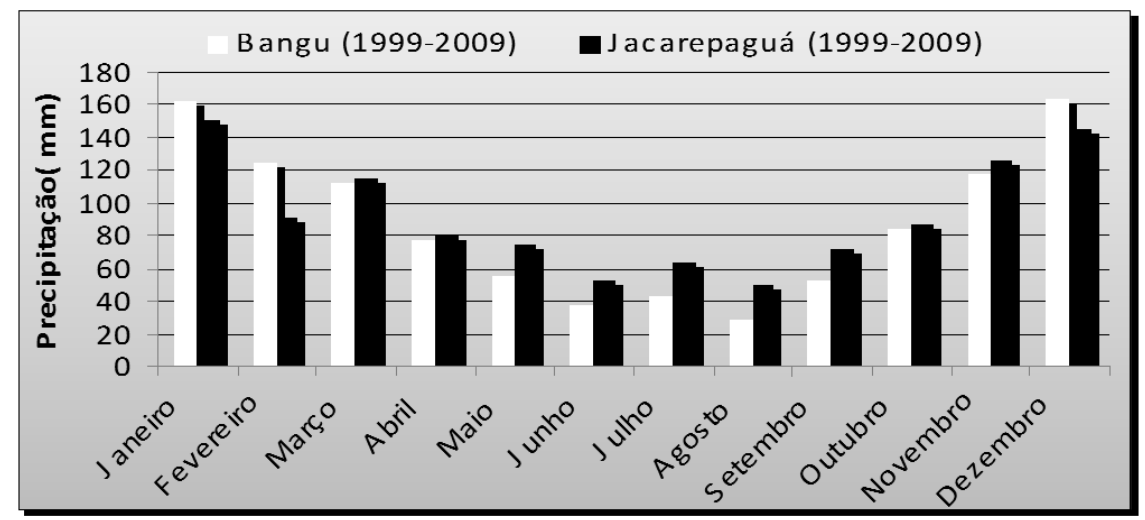

Figura 5 - Precipitação Média Msal de Jacarepaguá e Bangu (1999-2009) Fonte: (BRANDÃO \& MIRANDA) - Base de dados GEO-RIO

\section{Temperaturas em Bangu e Jacarepaguá}

Apesar da temperatura do ar ser um fator menos limitante que as chuvas no desenvolvimento de incêndios florestais, a combinação temperatura-umidade condiciona o processo de combustão seja ela espontânea e/ou criminosa.

A temperatura do ar é, portanto, um dos elementos meteorológicos que tem grande importância na origem dos incêndios, pois sua influência ocorre sobre a combustibilidade da mata, facilitando a evaporação e consequentemente diminuindo o grau de umidade da serrapilheira (MCIF, 2006). Sendo importante também que se ressalte que, o frio também pode aumentar significativamente o risco de incêndios por meio do ressecamento ou da queima da vegetação, especialmente em locais onde há registros de ocorrência de geadas (ICMBIO, 2010).

$\mathrm{Na}$ (FIGURA 6) identificam-se as médias mensais de temperatura nos bairros de Bangu e Jacarepaguá. Nessa figura se observa que a temperatura média mensal mais elevada ocorre nos mês de fevereiro $\left(\approx 29^{\circ} \mathrm{C}\right)$ enquanto as mais baixas temperaturas se manifestam nos meses de julho $\left(\approx 23^{\circ} \mathrm{C}\right)$. Já a oscilação média anual da temperatura do ar chega a $6^{\circ} \mathrm{C}$. Indicando que a região estudada, por se encontrar em meio montanhoso, os meses de verão e inverno apresentam padrões de temperatura do ar ligeiramente distintos. No que se refere às temperaturas máximas absolutas, Bangu alcança os maiores valores durante o verão (dezembro a março), atingindo nesse período valores de temperatura máxima absoluta de até $42,7^{\circ} \mathrm{C}$. Em contrapartida, Jacarepaguá apresenta temperaturas máximas absolutas que geralmente não ultrapassam os $39,6^{\circ} \mathrm{C}$. Em suma, pelo apresentado na (FIGURA 6), em se tratando do elemento temperatura do ar, a dispersão dos totais mensais e anuais em torno dos seus respectivos valores médios é em geral pequena. O que permite que se confirmem as conclusões de Hubard (1999) de que num raio de ação de até $100 \mathrm{~km}$ é muito pequena a variabilidade espaço temporal das médias de temperatura do ar.

Em se tratando do entorno da região onde está localizado o PEPB, Brandão (2003) constatou que os bairros de Bangu, Campo Grande e Realengo são os mais quentes no tocante aos valores máximos absolutos (entre $40^{\circ} \mathrm{C}$ e $42^{\circ} \mathrm{C}$ ). Nesses locais, a sotavento do maciço da Pedra Branca, verificam-se altos registros da temperatura, que se devem a influência do aquecimento catabático do ar. Ou seja, a região está, durante todo o ano, sujeita à ventilação fraca e/ou à ocorrência de frequentes períodos de calmarias devido o estreitamento provocado pela presença dos maciços do Gericinó-Mendanha e Pedra Branca. 


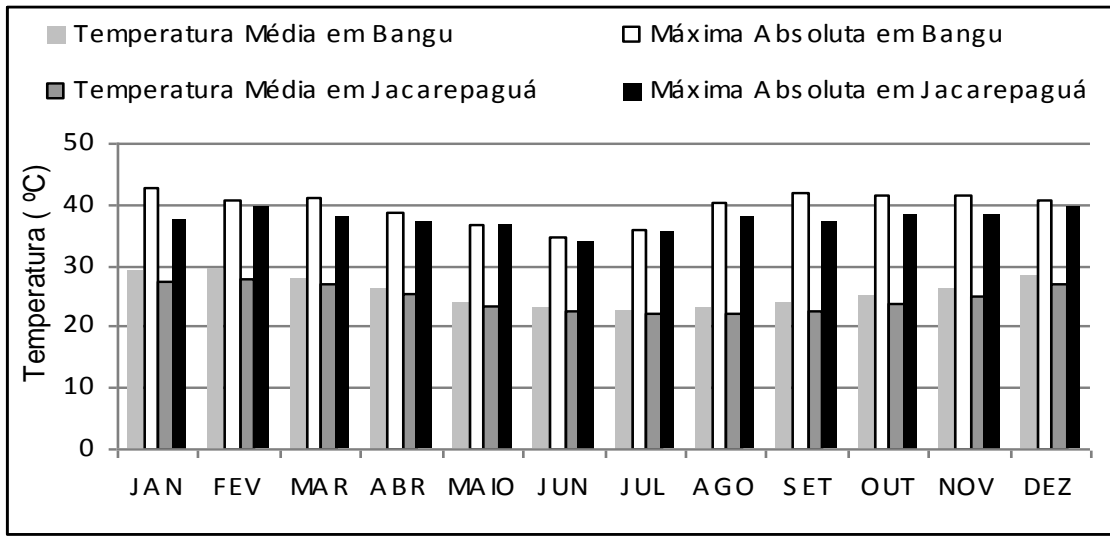

Figura 6 - Temperatura média e máxima absoluta em Bangu e Jacarepaguá (1993-2003) Fonte: (BRANDÃO \& MIRANDA) - Base de dados INMET

\section{Relação balanço hídrico X Riscos de incêndios florestais}

Sob a ótica bioclimática, a prática tem mostrado que o melhor meio de conhecer as disponibilidades térmicas e hídricas de uma determinada região é através do balanço hídrico climatológico (AZEVEDO e da SILVA, 2000). Para se estudar o fator umidade do clima, não basta avaliar os dados da precipitação pluviométrica individualmente. É indispensável também que se considerem as perdas de água do solo para atmosfera (evapotranspiração) como elemento de identificação climática: assim a caracterização de um clima seco ou úmido estaria ligada à pluviometria e às necessidades hídricas regionais.

Portanto, nessa seção optou-se, a partir dos dados da temperatura e precipitação pluviométrica, em se utilizar também, informações agregadas ao cálculo do balanço hídrico climatológico proposto por D'angionella (2003) para se verificar as diferenciações de caráter espaço-temporal entre meses secos e chuvosos para os bairros de Bangu e Jacarepaguá baseados na classificação de Thornthwaite (1948).

\subsubsection{Balanço hídrico na vertente Norte - Bangu}

De acordo com o apresentado na (FIGURA 7) a relação de um período do ano ser seco ou úmido estaria associada à relação entre a precipitação pluviométrica e a evapotranspiração potencial (ETP).

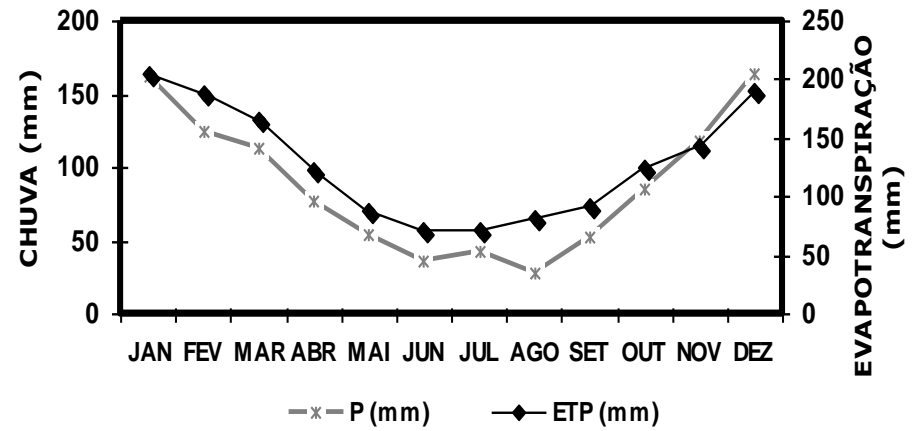

Figura 7 - Distribuição dos índices de disponibilidades hídricas na vertente norte (Bangu-1999-2009) de acordo com critérios propostos por Thornthwaite (1948). Fonte: (BRANDÃO \& MIRANDA)

Tendo como referência o bairro de Bangu, localizado na vertente norte do maciço da Pedra Branca, no mês de dezembro as taxas que representam a evapotranspiração potencial se mantiveram abaixo da taxa média das chuvas mensais. Portanto, somente o mês de dezembro ( $P>E T P)$ é representado por um período onde há reposição de água no solo e não de excedente hídrico na região. A evapotranspiração potencial apresentou valores oscilando entre $81,4 \mathrm{~mm}$ (agosto, trimestre mais seco) e 190,9 (dezembro, mês mais chuvoso). Nesse bairro, de acordo com os critérios propostos por Thornthwaite (1948), não se verifica um período do ano que apresente um excedente hídrico representativo para que se afirme que nesse mês e/ou período a vertente norte permaneça isenta de risco de incêndios florestais. Durante o 
inverno (Junho a Agosto) a deficiência hídrica é máxima oscila entre $31,8 \mathrm{~mm}$ (Junho) a 48,2 $\mathrm{mm}$ (agosto). Nesses meses de inverno o risco de incêndios por meio do ressecamento da vegetação é mais significativo.

\section{Balanço hídrico na vertente Leste - Jacarepaguá}

De acordo com o apresentado na (FIGURA 8), na vertente leste do maciço da Pedra Branca representada pelo bairro de Jacarepaguá, a relação de um período do ano ser seco ou úmido, ao contrário da vertente norte onde essa relação se diferencia acentuadamente, se apresenta com períodos onde as taxas de ETP superam as precipitações pluviométricas $(P)$ e períodos em que as chuvas superam as demandas evapotranspirativas.

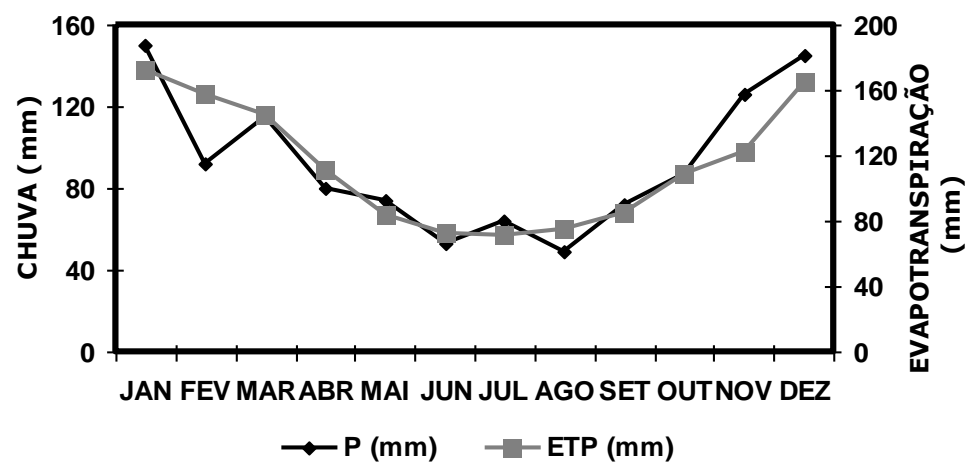

Figura 8 - Distribuição dos índices de disponibilidades hídricas na vertente leste (Jacarepaguá-19992009) de acordo com critérios propostos por Thornthwaite (1948). Fonte: (BRANDÃO \& MIRANDA)

Em Jacarepaguá, bairro localizado na vertente leste do maciço da Pedra Branca observa-se que, como ocorrido em Bangu, os períodos entre novembro e dezembro representam um período de reposição de água no solo. A evapotranspiração potencial apresentou valores médios entorno de 140, $0 \mathrm{~mm}$ na quadra mais chuvosa do ano (novembro a janeiro). Em contrapartida, durante os meses mais frios, observou-se que as taxas médias da evapotranspiração potencial oscilam na faixa de $70 \mathrm{~mm} / \mathrm{mês}$. Muito embora se tenha observado que durante os anos da série analisada (1999-2009), foram identificados períodos apresentando taxas variáveis de deficiência hídrica em dez dos doze meses do ano. Apesar de não se verificar um único mês com algum excedente hídrico, observa-se que nessa porção do maciço da Pedra Branca entre meses de fevereiro a abril a ocorrência de deficiência hídrica média de $23 \mathrm{~mm}$ e que a exceção do mês agosto $(\approx 21,2 \mathrm{~mm})$ quase não há registros de deficiência hídrica representativas no inverno.

As séries históricas de temperatura e precipitação corroboram com as informações do balanço hídrico climatológico, informando tendências climáticas distintas na região do Parque Estadual da Pedra Branca e permitindo concluir que a vertente norte é a porção do maciço que possui maior deficiência hídrica, sobretudo no inverno, e que possui as temperaturas médias mais elevadas em relação às outras porções do maciço. Tal conjuntura na vertente norte aumenta as probabilidades de incêndio na região e ratifica a tendência do local ser o detentor de maior número de incêndios de acordo com os dados do corpo de bombeiros.

$\mathrm{Na}$ figura 9 observa-se a associação dos vários elementos correlacionados aos incêndios florestais na vertente norte da Pedra Branca.

O esquema da (FIGURA 9) representa, portanto, a área do maciço que deveria ser considerada prioritária na tomada de ações mitigadoras de impactos gerados pelo fogo em vegetação. 


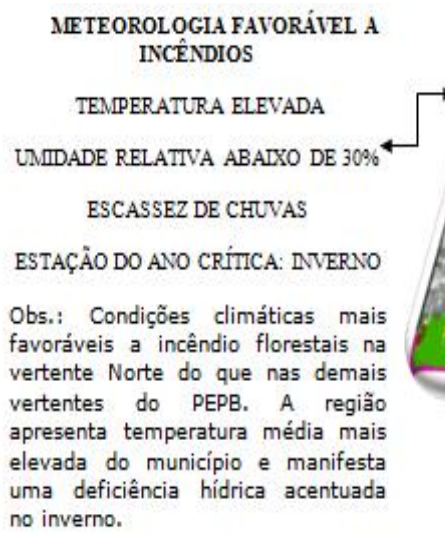

COBERTURA E USO DO SOLO ENCONTRADO NA VERTENTE NORTE DO PEPB
TIPOS DE VEGETAÇÄO-COMBUSTIVEIS FLORESTAIS:
FLORESTA NATURAL: RISCO MODERADO
ÁREAS DE CAMPO: RISCO EXTREMO
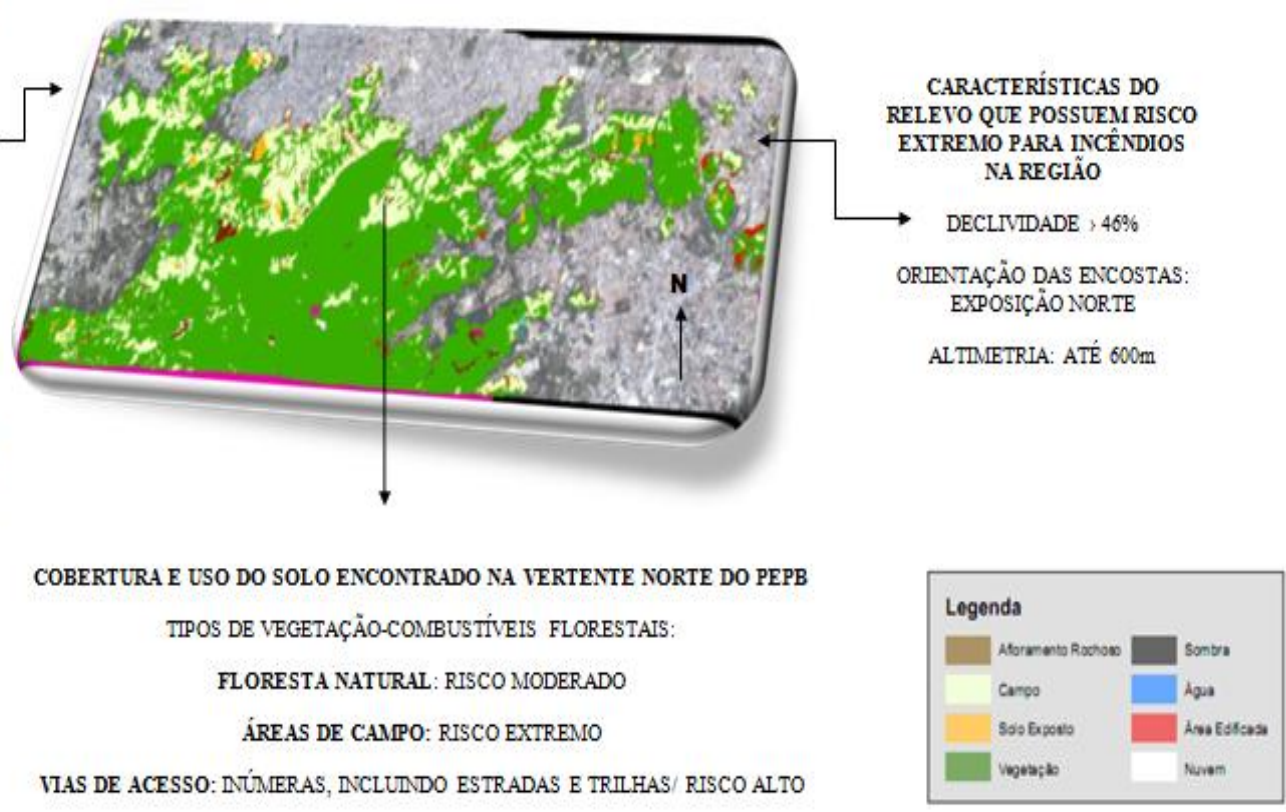

Figura 9 - Esquema de vulnerabilidades da vertente norte do maciço da Pedra Branca-RJ Fonte: (BRANDÃO \& MIRANDA)-Imagem do projeto PIMAR-2010

\section{Relação elemento meteorológico X incêndios no PEPB: Um estudo de caso}

$\mathrm{Na}$ (TABELA 2) são apresentadas as condições prevalecentes do tempo identificados nos dias do ano onde ocorreu maior número de incêndio no PEPB nos bairros de Bangu e Realengo durante os meses de julho e agosto do ano de 2006. Ressalta-se que dentre as ocorrências registradas no entorno do PEPB, 95\% delas ocorreram na vertente norte onde se localizam os bairros de Realengo e Bangu.

Tabela 2

Identificação de datas e condições meteorológicas durante incêndios nos meses de julho e agosto de 2006

\begin{tabular}{|c|c|c|c|c|}
\hline Ano 2006 & & & & \\
\hline Mês de Julho & $\begin{array}{l}\text { Número de Ocorrências } \\
\text { de Incêndio por dia }\end{array}$ & Ventos & Temperatura & Precipitação \\
\hline Data 22/07/06 & 2 & $3 \mathrm{~m} / \mathrm{s}$ & $35,0^{\circ} \mathrm{C}$ & 0,0 \\
\hline Data 24/07/06 & 1 & $5 \mathrm{~m} / \mathrm{s}$ & $35,4^{\circ} \mathrm{C}$ & 0,0 \\
\hline Data 25/07/06 & 3 & $6 \mathrm{~m} / \mathrm{s}$ & $30,0^{\circ} \mathrm{C}$ & 0,0 \\
\hline Data 28/07/06 & 2 & $8 \mathrm{~m} / \mathrm{s}$ & $35,6^{\circ} \mathrm{C}$ & 0,0 \\
\hline Data 29/07/06 & 1 & $7 \mathrm{~m} / \mathrm{s}$ & $25,6^{\circ} \mathrm{C}$ & \\
\hline \multicolumn{5}{|l|}{ Mês de Agosto } \\
\hline Data $16 / 08 / 06$ & 2 & $7 \mathrm{~m} / \mathrm{s}$ & $35,0^{\circ} \mathrm{C}$ & 0,0 \\
\hline Data 26/08/06 & 1 & $5 \mathrm{~m} / \mathrm{s}$ & $34,0^{\circ} \mathrm{C}$ & 0,0 \\
\hline
\end{tabular}

Fonte: (BRANDÃO,C.B \& MIRANDA.R.A.C,2011) - Base de dados RJ CLIMA

Pelo observado, o mês de julho de 2006, período onde houve maior percentual de incêndios durante a década analisada, somente três sistemas frontais alcançaram o Estado do Rio de Janeiro causado por um forte bloqueio atmosférico no Oceano Pacífico que impediu o avanço das frentes frias que ingressariam no país (DERECZYNSKI et al., 2009). Ressalta-se ainda, que o primeiro sistema frontal do mês a atuar no Estado, no dia 3 de julho, teve fraca intensidade, apenas aumentando a nebulosidade local e ocasionando chuvas leves e chuviscos em poucas localidades. Nos dias 10 e 11 de julho, a segunda frente fria alcançou o litoral do Rio de Janeiro, também de fraca atuação, somente favorecendo o aumento da nebulosidade e 
a ocorrência de chuviscos. Uma terceira zona de transição entre uma massa de ar frio e quente deslocou-se rapidamente pelo Estado do Rio no dia 30 de julho, acarretando a ocorrência de chuvas moderadas a fortes além de fortes rajadas de ventos na região do PEPB (RJ CLIMA, 2006). Em suma, pelas informações contidas na (TABELA 2) se verifica que, no dia 26/07, foi registrado a maior média diária da temperatura do ar $\left(\approx 36^{\circ} \mathrm{C}\right)$ em Bangu após longo período de estiagem. A despeito do mencionado acima, o mês de julho apresenta uma média mensal de $41 \mathrm{~mm}$ para o mês de julho no período compreendido entre 1999-2009 em Bangu (DERECZYNSKI et al., 2009), porém em julho de 2006 se registrou um total precipitado de 15 $\mathrm{mm}$ no mês, distribuídos em 3 dias de chuva.

No mês de agosto de 2006 as condições meteorológicas prevalecentes também se assemelharam ao mês anterior, apresentando temperaturas acima dos $30^{\circ} \mathrm{C}$ e ventos de 5 a 7 $\mathrm{m} / \mathrm{s}$ nos dias 16 e 26 de agosto. Pelo apresentado na (TABELA 2) se verificou que após o dia mais quente do mês (dia 15/08), com uma temperatura média de $36,7{ }^{\circ} \mathrm{C}$ houve duas ocorrências de incêndio no dia 16/08. Ressalta-se ainda o fato de que o tempo só se modificou após o dia 28/08 quando foram registradas chuvas de $18 \mathrm{~mm}$.

Dereczynski et al. (2009), estudando a climatologia das chuvas no município do Rio de Janeiro, concluiu que o ano de 2006 dentro da década (1999 a 2009) estudada foi o ano onde ocorreu um acentuado declínio das precipitações, sobretudo durante os meses de inverno.

Outro fator importante a se salientar quanto à ignição e propagação do fogo é a frequência dos eventos de chuva por períodos de 24 horas. Pelos estudos de Dereczynski et al (2009) se verifica que, durante o inverno, as chuvas diminuem sua frequência em relação às outras estações do ano, tendendo a chover menos no período da manhã e da tarde. Os baixos níveis de precipitação associados à baixa frequência de chuvas durante a manhã e tarde aumentam a suscetibilidade a incêndios, principalmente por ser o período do dia em que a radiação solar está no seu ápice.

\section{CONSIDERAÇÕES FINAIS}

Em ecossistemas florestais típicos como o do Parque Estadual da Pedra Branca - PEPB as causas de incêndio são variáveis, sendo, porém, a maioria originária pela ação antrópica, já que os incêndios naturais pertencem a uma pequena parcela dentre o número total de ocorrências. Mas em ambas as situações as condições geográficas e da atmosfera em determinado local, seja numa escala momentânea (condições do tempo), ou por um período longo de muitos anos num padrão que ser repete (condições de clima) são capazes de atuar de forma a intensificar e propagar os incêndios por grandes extensões florestais, aumentando durante os meses mais propícios a incêndios os danos causados ao meio ambiente.

No tocante aos padrões climáticos, se conclui que em Bangu, no mês de dezembro, o solo apresenta alguma umidade, porém durante o restante do ano Bangu encontra-se com deficiência hídrica associada a temperaturas médias e máximas absolutas sempre mais elevadas se comparadas com a vertente Leste do PEPB. Tal deficiência hídrica poderia estar correlacionada à topografia local que propicia a distribuição irregular da precipitação, contribuindo para um clima mais seco e para uma vegetação naturalmente menos densa nas regiões das vertentes ao Norte. Juntamente com as características acima mencionadas a vertente norte do PEPB apresenta uma crescente ocupação ilegal de moradias, que atuam como vetores no aumento do desmatamento, poluição e erosão, substituindo gradativamente a cobertura vegetal nativa, embora já sejam naturalmente menos densa, por gramíneas que possuem alto potencial de combustibilidade.

$\mathrm{Na}$ vertente Leste representada pelo bairro de Jacarepaguá se verifica que somente em fevereiro (verão) e agosto (final do inverno) são registrados climatologicamente períodos propícios à combustão nessa face do maciço. Nessas regiões as temperaturas são mais amenas por receberem a ação direta das brisas marinhas que suavizam as temperaturas em bairros como Jacarepaguá, Barra e Recreio. As chuvas orográficas a barlavento possibilitam também uma formação vegetal mais desenvolvida e densa, dificultando a combustão devido ao seu menor grau de combustibilidade. Destaca-se, portanto, que apesar da vertente leste se apresentar climatologicamente com alguns períodos do ano também propícios a incêndios, que a associação dos demais fatores, como: as características da vegetação, exposição aos raios solares, topografia e as influências da maritimidade, atuam como um somatório positivo contra os incêndios nesta região. Contudo, é importante esclarecer que as vertentes leste e oeste já vêm sendo degradadas pela ação do homem, possibilitando que algumas características físicas 
naturais, que conferem que estes locais tenham menores propensões a incêndios, possam se reverter ao longo dos anos.

Tendo como base no índice de aridez, definido por Thornthwaite, em Bangu este foi estimado com Ia $=19,4$ o que significa que nessa vertente do maciço predomina clima com deficiência hídrica moderada no verão. Em contrapartida, na vertente leste, representada pelo bairro de Jacarepaguá por apresentar sem ou com pequena deficiência hídrica durante dez dos doze meses do ano representa a face do maciço estudada com menor risco de incêndios florestais. Esses resultados permitiram se concluir que existe uma relação entre os valores gerados pelo índice climático estimado a partir do balanço hídrico de Thornthwaite com a precipitação pluviométrica, indicando a possibilidade de desenvolvimento de um sistema de alerta baseado na variável meteorológica, associado com informações de caráter geográfico.

Durante um inverno bem definido, com temperaturas amenas, o risco de incêndios florestais diminui, porém é durante alguns invernos mais atípicos, com elevadas temperaturas associadas à estiagem e a presença de constantes bloqueios atmosféricos é que o risco se acentua, fato ressaltado no estudo de caso do ano de 2006, que demonstrou a influência das elevadas temperaturas com a seca causada pelas poucas passagens de fenômenos meteorológicos associados a chuvas intensas.

Portanto, cada região do Estado do Rio de Janeiro possui diferenciações em termos climatológicos e geográficos, havendo por isso a necessidade de investigar cada elemento associado aos incêndios para que se aumentem os sucessos na prevenção e na supressão contra os incêndios florestais.

\section{REFERÊNCIAS}

.AZEVEDO, P.V., da SILVA, G.B. Potencial agroclimático da região da "Chapada Diamantina" no Estado da Bahia. Revista Brasileira de Meteorologia. v.15, n.1, p.77-88, 2000.

.BATISTA, A. C. Mapas de risco: uma alternativa para o planejamento de controle de incêndios florestais. Revista Floresta, Curitiba. v. 30, n.1,p 45-54, 2000.

Determinação de umidade do material combustível sob povoamentos de Pinus taeda.1984.61f.(dissertação de mestrado), Universidade Federal do Paraná, Curitiba, 1984.

.BATISTA, A.C. e SOARES, R.V. Manual de prevenção e combate a incêndios florestaiscursos de treinamento em controle de incêndios florestais. Fundação de Pesquisas Florestais do Paraná. Curitiba-Paraná. 2003. 68p.

.BRANDÃO, A.M. O clima urbano na cidade do Rio de Janeiro. In: MONTEIRO, C.A. de F. \& MENDONÇA, F. (orgs), Clima Urbano. São Paulo: Contexto, 2003, p.121-154.

.BROWN, A.A. e DAVIS, K.P. Forest fire-control and use.2 ed. New York: McGraw Hill, 1973. $686 \mathrm{p}$.

.CEBERJ - Corpo de Bombeiros do Rio de Janeiro. Termodinâmica da combustão. 2010. Disponível em http://www.cieb.cbmerj.rj.gov.br/documentos/Material.../Cap_1.pdf. Acessado em 25/01/2011

.COSTA.N.M.C et al. Definição e caracterização de áreas de fragilidade ambiental, com base em análise multicritério, em zona de amortecimento de unidade de conservação. 17p.2003. Disponível em: http://egal2009.easyplanners.info/area04/4036_Costa_Nadja_Maria _Castilho da.pdf. Acesso em: 25/02/2010.

COURA P.H.F et al. Mapeamento geoecológico da susceptibilidade à ocorrência de incêndios no maciço da Pedra Branca, município do Rio de Janeiro. Anuário do Instituto de Geociências, 2009; 32 (2):14-25.

.D'ANGIONELLA, G.L.B. Avaliação de métodos para estimativa da evapotranspiração e cálculo do balanço hídrico na mesorregião Sul da Bahia. 2003. 64f. Tese (Mestrado em Ciências Agrárias) - Curso de Pós-Graduação em Ciências Agrárias, Faculdade de Agronomia e Medicina Veterinária, Universidade de Brasília, 2003.

.DERECZYNSKI, C.P et al. Climatologia da precipitação no município do Rio de Janeiro. Revista Brasileira de Meteorologia, v.24, n1, p.24-38, 2009.

.GAYLOR,H.P.Wildfires- prevention and control. Bowie, MD: Robert J. Brady Co.; 1974, 319p. 
.GOLDAMMER, J. G. Incêndios florestais: prevenção, controle e uso do fogo. Irati: S.A.C.T,1982.93 p.

.HUBBARD, K.G. Spatial variability of daily weather variables in the high plains of the USA. Agricultural and Forest Meteorology. v.68, p. 29-41.1999.

.ICMBio/MMA- Instituto Chico Mendes de conservação da biodiversidade- Apostila para formação de brigadista de prevenção e combate a incêndios florestais. Brasília, 2010,87p.

.MCIF. Manual de combate a incêndios florestais. Coletânea de Manuais Técnicos de Bombeiros, $1^{\circ}$ Ed, v. 4, São Paulo, 2006.

.MONTEZUMA, R.C.M, OLIVEIRA.R. Os ecossistemas da baixada de Jacarepaguá e o PEU das Vargens ( parecer entregue ao Ministério Público do Estado do Rio de Janeiro). Disponível em: http://www.vitruvius.com.br/revistas/read/arquitextos/10.116/3385, Acesso em 28/02/2010.

.NIEUWOLT, S. Tropical Climatology: an introduction to the climates of the low latitudes. New. York: John Willey \& Sons, 1977. 207 p.

.OLIVEIRA, R.R et al.Classificação de estágios sucessionais na Mata Atlântica através de imagem IKONOS.Rio de Janeiro. $1^{0}$ Encontro Científico Parque Estadual da Pedra Branca, p.51-53, 2009.

.OLIVEIRA, R.R. et al. Significado ecológico de orientação de encostas no Maciço da Tijuca, Rio de Janeiro. Ecologia Brasiliensis, v.1, p.523-541, 1995.

.OLIVEIRA, R.R. As marcas do homem na floresta: História Ambiental de um trecho de Mata Atlântica. Rio de Janeiro, Ed: PUC - Rio, 2005, 232 p.

.PEREIRA, A.R.; ANGELOCCI, L.R. e SENTELHAS, P.C. Agrometeorologia: fundamentos e aplicações práticas. Livraria e Editora agropecuária. Rio Grande do Sul. 2002, 478p.

.PIMAR. Programa Integrado de Monitoria remota de fragmentos florestais e crescimento urbano no Rio de Janeiro. Relatório Trimestral- abril, maio e junho de 2010 NIMA,PUCRio.Disponívelem:http://www.nima.pucrio.br/sobre_nima/projetos/pimar/relatorios. php.

.PINTO, H.S. et al. Zoneamento de riscos climáticos para cafeicultura do estado de São Paulo. Revista Brasileira de Agrometeorologia, v. 9, n. 3, p.495-500, 2001.

.RJ-CLIMA. Boletim RJ CLIMA, 2006. Disponível em: http://www.simerj.com/default_rjclima.php. Acessado em agosto de 2010.

.SANT'ANNA NETO, J.L. A variabilidade temporal - espacial das chuvas no Estado de São Paulo no período de 1971-1993. IN: CONGRESSO BRASILEIRO DE AGROMETEOROLOGIA. 11., Florianópolis. CD-ROM, 1991.

.SOARES, R. V. e BATISTA, A.C. Incêndios Florestais - Controle e uso do fogo. Curitiba: Fundação de Pesquisas Florestais do Paraná, 1985, 123p.

Curso de especialização por tutoria à distância controle de incêndios florestais: o problema do fogo na floresta e meteorologia aplicada aos incêndios florestais: módulo 2. Brasília, DF: ABEAS, 2002, 120p.

.THORTHWAITE, C.W. An approach toward a rational classification of climate. Geographic Review. v.38, n.1, p.55-93.1948.

.THORTHWAITE, C.W.; MATTER, J.R. The water balance. Publications in Climatology, v. 8, n.1, Laboratory of Climatology, Drexel Institute of Technology, Centerton, New Jersey, $1955,104 p$.

.TRONCY, N.; MOLTENI, F., BOZZINI, M. A comparison of local approximation methods for the analysis of meteorological data. Archive Meteorological. Bioclimatology. v. 36, $\mathrm{p}$ 189-211. 1986.

Sites visitados:

http://www2.rio.rj.gov.br/georio.Acesso em: 14/03/2011.

http://www.guiapepb.infotrilhas.com/pepb_1/pepb.html.Acesso em:20/04/2012. 